\title{
A megathrust earthquake cycle model for Northeast Japan: bridging the mismatch between geological uplift and geodetic subsidence
}

\author{
Akinori Hashima ${ }^{1 *}$ (D) and Toshinori Sato ${ }^{2}$
}

\begin{abstract}
In Northeast Japan, it remains a puzzle to reconcile the mismatch between long-term (geological) uplift and lateinterseismic and coseismic subsidence associated with the 2011 Tohoku earthquake. To explain this mismatch between different periods, we modeled the entire megathrust earthquake cycle in the Northeast Japan arc using a simple dislocation model with a two-layered lithosphere-asthenosphere structure in which we account for viscoelastic relaxation in the asthenosphere and tectonic erosion. The model behaves differently when the rupture stops within the lithosphere and when it cuts through the lithosphere to reach the asthenosphere. It is possible to explain the mismatch in the case where the rupture stops within the lithosphere. In the early interseismic stage, the viscoelastic response to the megathrust earthquake dominates and can compensate for late-interseismic and coseismic subsidence. In contrast, the late-interseismic stage is dominated by the locking effect with the steady slip below the rupture area. Tectonic erosion explains up to about half of the long-term uplift by landward movement of arc topography. The rest of the long-term uplift may be attributed to indirect effects of internal deformation in the arc.
\end{abstract}

Keywords: Earthquake cycle, Vertical deformation, Dislocation theory, Viscoelasticity, Northeast Japan, The 2011 Tohoku earthquake

\section{Background}

The Northeast (NE) Japan arc is a typical island arc formed by the subduction of the Pacific plate under the Eurasian plate. It was thought that the maximum magnitude for interplate earthquakes would be M8 based on modern earthquake observation (Yamanaka and Kikuchi 2004), until the M9 2011 Tohoku earthquake occurred. This megathrust rupture reached to the trench with a maximum slip of $50 \mathrm{~m}$ (e.g., Yagi and Fukahata 2011) and resulted in a devastating tsunami. Studies of older tsunami deposits suggest a recurrence interval for megathrust earthquakes of 500-800 years (Sawai et al. 2012, 2015). Given that we can now expect the recurrence of an

\footnotetext{
*Correspondence: hashima@eri.u-tokyo.ac.jp

1 Earthquake Research Institute, University of Tokyo, Yayoi 1-1-1, Bunkyo-ku, Tokyo 113-0032, Japan

Full list of author information is available at the end of the article
}

earthquake with magnitude greater than M8, we should explore the tectonic implications in NE Japan of M9-class earthquake cycles.

The mismatch between long-term (geological) and short-term (geodetic) estimates of vertical deformation on the Pacific coast of NE Japan had already been recognized before the M9 earthquake (Ikeda 2003; Tajikara 2004; Matsu'ura et al. 2008, 2009). Marine terraces with the height up to $50 \mathrm{~m}$ formed during the last interglacial period (Stage 5e) show average uplift rate of $0.2-0.4 \mathrm{~mm} /$ year over NE Japan (Koike and Machida 2001), while leveling observations from the late nineteenth century showed subsidence of 3-6 mm/year (Dambara 1971; Kunimi et al. 2001). Ikeda (2003) pointed out the possibility of occurrence of a megathrust earthquake, which he assumed to cause uplift to cancel out late-interseismic subsidence and restore a long-term balance. In fact, additional subsidence of up to $1.2 \mathrm{~m}$ occurred during the 2011 
Tohoku earthquake (Nishimura et al. 2011). We now have to reconcile the mismatch between long-term uplift and late-interseismic and coseismic subsidence.

In the 5 years since the earthquake, postseismic vertical rebound of up to $\sim 40 \mathrm{~cm}$ has been measured on the Pacific coast which appears to recover the amount of coseismic subsidence in $\sim 100$ years, based on prediction of a functional fitting analysis of the time series of postseismic deformation (Nishimura 2014). In order to explain the late-interseismic subsidence using an elastic dislocation model, Ikeda (2014) and Nishimura (2014) had to assume interseismic locking down to a depth of $100 \mathrm{~km}$, where high shear stress is unlikely to be accumulated because of high temperature.

We attempt to reconcile the apparent mismatch by considering the change in vertical movement through an entire megathrust earthquake cycle, with particular attention to the effect of viscoelastic relaxation in the asthenosphere over time given a more than 500-year recurrence interval. Savage and Prescott (1978) first proposed an earthquake cycle model with the concept of dislocation for strike-slip earthquakes. Matsu'ura and Sato (1989) and Sato and Matsu'ura (1988) applied this model to subduction zones, showing that long-term deformation in subduction zones develops over repeated earthquake cycles. An important feature of the model is to prescribe slip motion on the plate interfaces as an input source, which may be accurately determined from modern seismological and geodetic observations. Hashimoto et al. (2004) showed that this method can well reproduce the deformation fields around Japan due to plate subduction. Sato and Matsu'ura (1993) extended the model to include the effect of stress relaxation in the lithosphere for longlasting subduction (typically longer than $10^{7}$ years) and the effect of tectonic accretion/erosion. Hashimoto et al. (2008) applied the extended model to long-term deformation in NE Japan. Focusing on late-interseismic and coseismic subsidence in NE Japan, Sagiya (2015) proposed a two-fault system with different recurrence intervals, based on the model of Matsu'ura and Sato (1989). Although the deep part of the fault was incorporated to account for the effect of observed M7-class earthquakes on vertical movement, the modeled fault area was about five times overestimated compared to the historical $\sim \mathrm{M} 7$ earthquakes. In fact, observed onland displacements for the recent M7-class earthquakes vary spatially (Suito et al. 2011). The Sagiya (2015) result might not represent the regional deformation pattern.

In this study, we apply the earthquake cycle model accounting for the effects of viscoelastic relaxation and tectonic erosion developed by Matsu'ura and Sato (1989), Sato and Matsu'ura (1993), and Hashimoto et al. (2008) to the megathrust earthquake cycle of the NE Japan arc.
Our goal is to understand the essential mechanism of the mismatch with a simple model consistent through different periods and not to fit calculation to the observation in detail.

\section{Tectonic setting}

Pacific plate motion for the past 42 My can be determined based on the trajectory of the Hawaiian-Emperor seamount chain (e.g., Sharp and Clague 2006). Around Japan, the current plate configuration was established around $15 \mathrm{Ma}$, when the opening of the Sea of Japan ended (Otofuji et al. 1985; Baba et al. 2007).

Sato (1994) synthesized the history of tectonic stress in NE Japan based on regional geology and determined that the stress regime was neutral or weakly extensional perpendicular to the trench immediately following the opening of the Sea of Japan. Around 3.5 Ma, the stress regime changed to strong compression. DSDP drilling and seismic reflection studies conducted offshore to the east in the area of the Japan Trench show a widely traceable submarine unconformity which is thought to have formed by subaerial erosion during the Paleogene after which the forearc subsided again (Nasu et al. 1980; von Huene et al. 1982). To explain this broad subsidence, von Huene and Lallemand (1990) proposed basal erosion of the overriding plate and estimated landward retreat of the overriding plate due to tectonic erosion by $3 \mathrm{~km} / \mathrm{My}$.

The rate of uplift over the land area of NE Japan for the past 150,000 years can be estimated geologically based on the heights of dated marine and fluvial terraces (Yoshiyama and Yanagida 1995; Koike and Machida 2001; Tajikara 2004; Tajikara and Ikeda 2005). The general trend over NE Japan is overall uplift at a rate of $0.2-0.4 \mathrm{~mm} /$ year (Fig. 1a). In contrast, 100-year leveling observations summarized by Kunimi et al. (2001) show subsidence of 3-6 mm/year on the east coast (Fig. 1b). Interseismic subsidence was also seen in tidal records during 19511981 (Kato 1983) and in decadal GPS observations (Suwa et al. 2006; Nishimura 2014). Coseismic deformation due to the 2011 Tohoku earthquake was reported by a dense GPS network (Nishimura et al. 2011), showing broad subsidence with small uplift on the west coast and eastward tilting (Fig. 1c).

\section{Earthquake cycle model with dislocations}

We assume a two-layered viscoelastic half-space with the thickness of the surface layer $H$ to represent the minimal rheological structure of the lithosphere-asthenosphere system (Fig. 2). The geometry of the upper surface of the Pacific slab is taken from a vertical section of the CAMP plate interface model (Hashimoto et al. 2004) at the hypocenter of the Tohoku earthquake (Fig. 1c), and we assume uniform geometry along a straight trench. The plate 


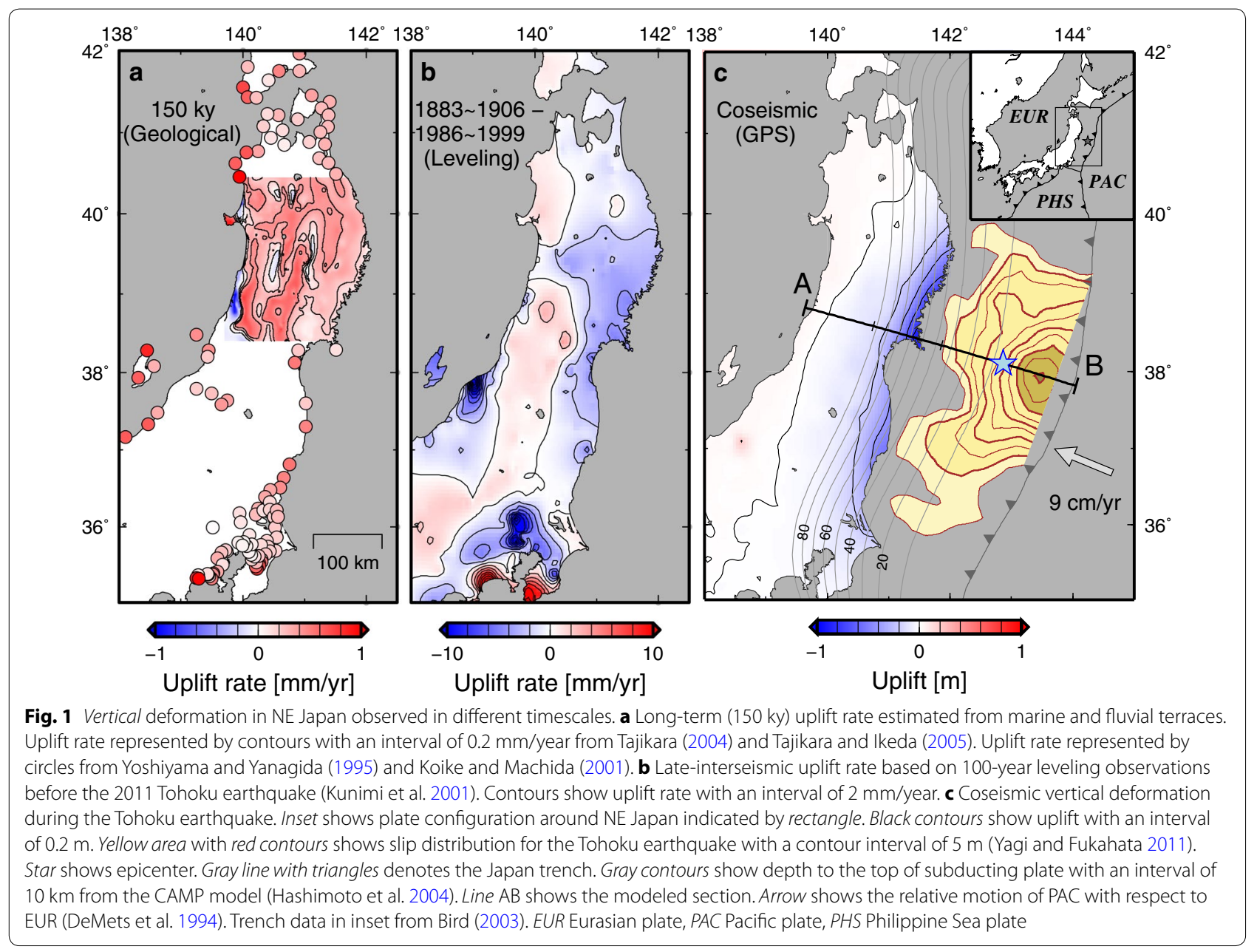

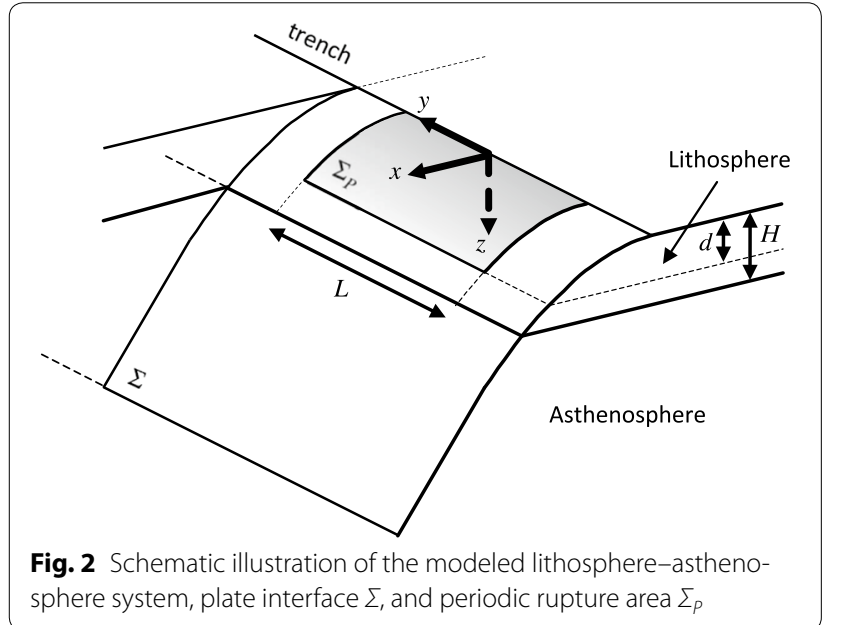

interface $\Sigma$, where dislocation (fault slip) is prescribed, is divided into two parts: $\Sigma_{P}$ is the area of periodic slip on a megathrust with a recurrence time $T$ and $\Sigma-\Sigma_{P}$ is the area of steady slip, moving at the rate of plate convergence $v_{p l} . \Sigma_{P}$ is taken as a rectangular area from trench to depth $d$, of length along the trench $L$. Here, $L$ is fixed at $500 \mathrm{~km}$ considering the length of the slip area of the Tohoku earthquake (e.g., Yagi and Fukahata 2011). We assume uniform slip over $\Sigma_{p}$ for simplicity.

The mechanical effect of tectonic erosion/accretion can be simply expressed by the advective term due to the landward/seaward migration of the plate boundary as the material removed from (or added to) the upper plate (Sato and Matsu'ura 1993; Hashimoto et al. 2008). For simplicity, we assume uniform erosion rate over the base of the upper plate shallower than the lithosphere-asthenosphere boundary. The migration rate $v_{e}$ is assumed to be $3 \mathrm{~mm} /$ year (von Huene and Lallemand 1990) and the duration of tectonic erosion $T_{e}$ is set at $3.5 \mathrm{My}$, considering the duration of the present compressive stress regime (Sato 1994). Assuming the viscosity of the lithosphere and asthenosphere to be $10^{23}-10^{24}$ and $10^{18}-10^{19} \mathrm{~Pa} \mathrm{~s}$, respectively, the effective stress relaxation time of the lithosphere $T_{L}$ and asthenosphere $T_{A}$ become $10^{7}$ years 
and $10^{2}$ years, respectively (Sato and Matsu'ura 1993). Following Hashimoto et al. (2008), we applied the formulation for tectonic erosion, which assumes $T_{A} \ll T_{e} \ll T_{L}$, and $T_{L} \ll T_{S}$, where $T_{S}$ denotes the duration of steady subduction. This assumption corresponds to "moderate-aged subduction" in Hashimoto et al. (2008), where response to the steady tectonic erosion of a two-layered viscoelastic lithosphere-asthenosphere system can be approximated by the response of elastic lithosphere overlying the completely relaxed ( $t \rightarrow \infty$ limit) asthenosphere. In fact, $T_{e}, T_{L}$, and $T_{S}$ differ by factors, so the real effect of tectonic erosion may decay to some degree by viscous relaxation in the lithosphere. Still, main features can be expressed in this formulation.

Under the above conditions, the three-dimensional displacement fields are obtained by integrating the response to slip distributed over $\Sigma$. Taking as a reference frame the configuration of the ground surface just after the occurrence of a great earthquake, the vertical deformation cycle $(0 \leq t<T)$ can be expressed as follows,

$$
\begin{aligned}
\Delta u(\boldsymbol{x}, t)= & -v_{p l} T_{e} v_{e} t \frac{\mathrm{d}}{\mathrm{d} \boldsymbol{x}} u_{\mathrm{s}}^{E}(\boldsymbol{x})-v_{p l} t u_{p}^{E}(\boldsymbol{x}) \\
& +v_{p l} T \sum_{k=0}^{\infty}\left[u_{p}(\boldsymbol{x}, k T+t)-u_{p}(\boldsymbol{x}, k T)\right] \quad(0 \leq t<T)
\end{aligned}
$$

with

$$
\begin{aligned}
u_{\mathrm{s}}^{E}(\boldsymbol{x}) & \equiv \int_{\Sigma} q^{E}\left(\boldsymbol{x} ; \boldsymbol{x}^{\prime}\right) \mathrm{d} \boldsymbol{x}^{\prime}, u_{p}^{E}(\boldsymbol{x}) \equiv \int_{\Sigma_{P}} q^{E}\left(\boldsymbol{x} ; \boldsymbol{x}^{\prime}\right) \mathrm{d} \boldsymbol{x}^{\prime}, u_{p}(\boldsymbol{x}, t) \\
& \equiv \int_{\Sigma_{P}} q\left(\boldsymbol{x}, t ; \boldsymbol{x}^{\prime}, 0\right) \mathrm{d} \boldsymbol{x}^{\prime}
\end{aligned}
$$

where $q\left(\boldsymbol{x}, t ; \boldsymbol{x}^{\prime}, \tau\right)$ is the response of an elastic-viscoelastic half-space (i.e., elastic lithosphere overlying viscoelastic asthenosphere) to a unit step slip at $\left(\boldsymbol{x}^{\prime}, \tau\right)$, and $q^{E}\left(\boldsymbol{x} ; \boldsymbol{x}^{\prime}\right)=q\left(\boldsymbol{x}, t \rightarrow \infty ; \boldsymbol{x}^{\prime}, 0\right)$. In this case, we can take advantage of an analytic expression for an elastic-viscoelastic two-layered half-space including a gravitational effect (Fukahata and Matsu'ura 2005, 2006). Equation (1) is the same as Eq. (10) of Matsu'ura and Sato (1989) except that the first term is replaced by the right-hand side of Eq. (20) of Hashimoto et al. (2008), which represents the contribution of tectonic erosion. Note that this term is an approximated expression applicable to the deformation far from the source (Hashimoto et al. 2008). The second term represents the effect of increasing slip deficit (interseismic locking). Locking rate could change in several years (e.g., Nishimura et al. 2004; Mavrommatis et al. 2014, 2015), but this change can be regarded as short-time perturbation from the general trend of slip deficit accumulation through the interseismic stage. It must be noted that the long-lasting locking is expressed by a relaxed term, which means that interseismic deformation pattern is different from the inverse of instantaneous (coseismic) response. The third term represents the effect of viscoelastic relaxation in the asthenosphere due to periodic ruptures. As Matsu'ura and Sato (1989) showed, the second and third terms cancel out after the occurrence of the next earthquake at $t=T_{+}$and only the first term is accumulated through repeated earthquake cycles; it represents permanent geological (long-term) deformation. In other words, long-term deformation is independent of interseismic process. Displacement rates can be obtained by differentiating Eq. (1) with respect to time $t$. The displacement rates due to tectonic erosion and locking are constant in time, but the viscoelastic effect decays with time.

If we assume a steady slip rate equal to relative plate velocity $\left(v_{p l}=9 \mathrm{~cm} /\right.$ year) (DeMets et al. 1994) and a megathrust rupture interval of $T=500$ years on $\Sigma_{P}$ (Sawai et al. 2012, 2015), the amount of coseismic slip is $45 \mathrm{~m}$. The material parameters except for viscosity are listed in Table 1. We compute the evolution of vertical displacement for various values of structural parameters (lithospheric thickness $H$, depth to lower edge of periodic rupture area $d$, and viscosity in the asthenosphere $\eta_{a}$ ).

\section{Results}

We show results of our calculations for two cases, Case 1: $d=H=35 \mathrm{~km}$, where the megathrust earthquake cuts completely through the lithosphere, Case $2: d=25 \mathrm{~km}$, $H=35 \mathrm{~km}$, where the megathrust rupture stops in the lithosphere, while its unruptured lower end continues to slip steadily. In both cases, $\eta_{a}=10^{19} \mathrm{~Pa}$.

Figure 3 shows changes with time in profiles of the cumulative vertical displacement (Fig. 3a, b) and vertical deformation rate (Fig. 3c, d) over an earthquake cycle on a vertical plane bisecting the periodic rupture area $\Sigma_{P}$ (corresponding to the cross section under line $\mathrm{AB}$ in Fig. 1c) for Case 1. The land area (235-390 km from the trench) is indicated by white area. Coseismic subsidence (Fig. 3a) peaks at $\sim 200 \mathrm{~km}$ from the trench, and the area of subsidence extends landward (westward) with decay, as observed (Nishimura et al. 2011). The initial rate of postseismic uplift (Fig. 3c) peaks in the coseismic

Table 1 Material parameters used in numerical simulations

\begin{tabular}{lllll}
\hline & $\boldsymbol{h}(\mathbf{k m})$ & $\boldsymbol{\rho}\left(\mathbf{k g} / \mathbf{m}^{\mathbf{3}}\right)$ & $\boldsymbol{K}(\mathrm{GPa})$ & $\boldsymbol{\mu}(\mathrm{GPa})$ \\
\hline Lithosphere & $H$ & 2800 & 60 & 35 \\
Asthenosphere & $\infty$ & 3400 & 125 & 65
\end{tabular}

$h$ thickness of layer, $\rho$ density, $K$ bulk modulus, $\mu$ rigidity 

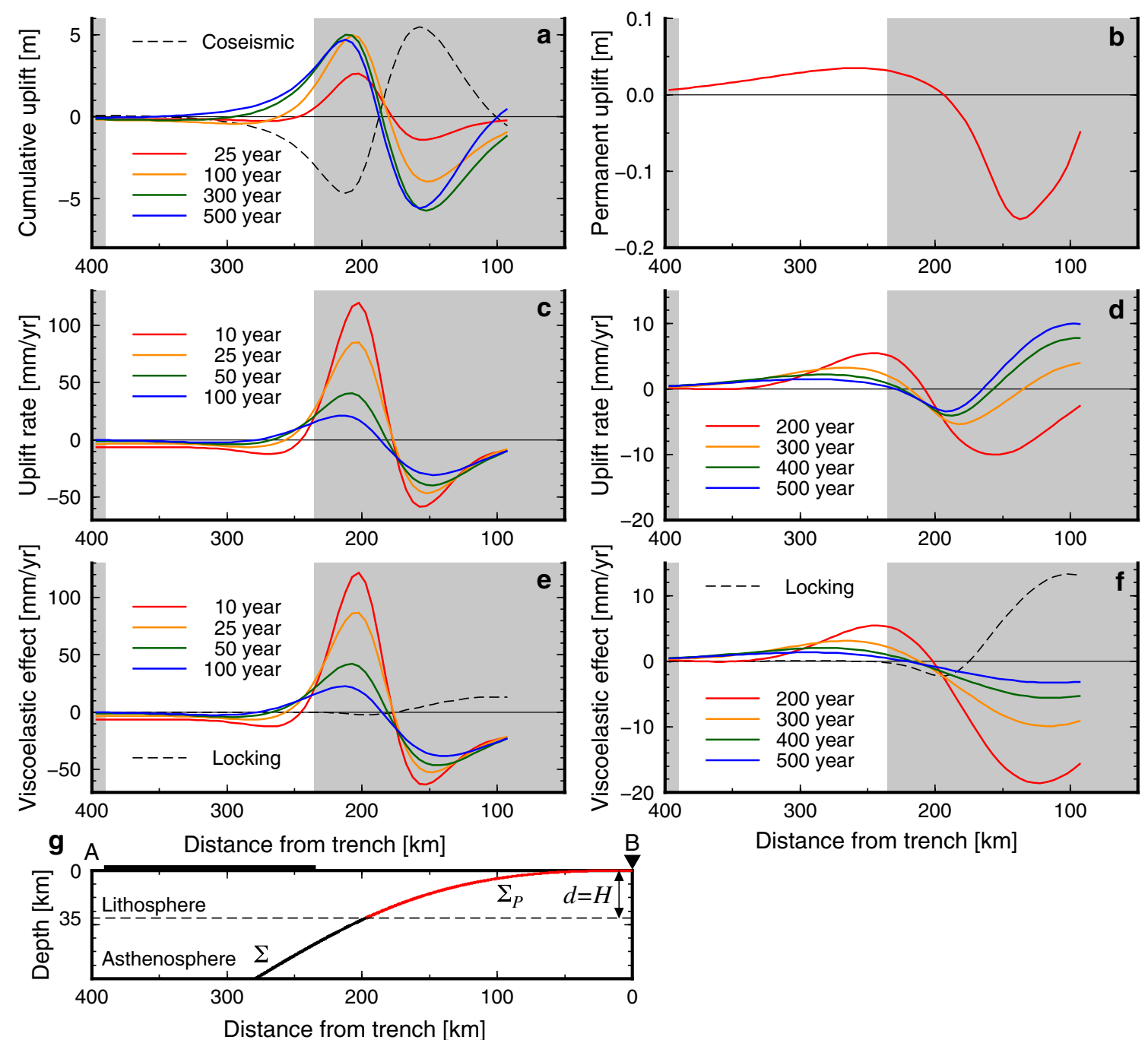

Fig. 3 Temporal change in cumulative uplift and uplift rate in an earthquake cycle on a vertical plane bisecting the periodic rupture area (corresponding to the cross section under line AB in Fig. 1c) for Case 1. White and gray areas in panels a-f denote land and ocean in NE Japan, respectively. a Cumulative uplift after a megathrust earthquake. Dashed line shows coseismic uplift profile. b Permanent uplift due to an earthquake cycle. c Uplift rate in the first 100 years of an earthquake cycle. $\mathbf{d}$ Uplift rate after 200 years of an earthquake cycle. $\mathbf{e}$ Contribution of the effect of viscoelastic relaxation to the uplift rate in the first 100 years compared with the locking effect. Locking and viscoelastic effects are calculated by separately evaluating the second and third terms of the right-hand side of Eq. (1), respectively. $\mathbf{f}$ Contribution of the effect of viscoelastic relaxation after 200 years. Note that the dashed line is the same for panels $\mathbf{e}$ and $\mathbf{f} . \mathbf{g}$ Geometry of plate interface along line AB (Fig. 1c). Solid line shows the plate interface $\Sigma$, with red part denoting periodic rupture area $\Sigma_{p}$. Dashed line shows the lithosphere-asthenosphere boundary. Thick solid line shows the land area. Triangle shows the location of the trench

subsidence area, then gradually shifts landward, and decreases. In the first 100 years, uplift mainly occurs offshore, but after 200 years it migrates landward (Fig. 3d). Just before the next earthquake ( $t=500$ years), almost all of the land is being uplifted. The total deformation profile becomes similar to the inverse of the coseismic profile at $t=500$ years (Fig. 3a). Following the end-cycle earthquake, most of the vertical deformation cancels out, but a small amount of uplift remains (Fig. 3b). This remnant displacement accumulates over repeated earthquake cycles to become permanent geological deformation with a rate of $\sim 0.08 \mathrm{~mm} /$ year $(\sim 0.04 \mathrm{~m}$ in 500 years). The calculated land uplift and marine subsidence pattern is consistent with the observed (e.g., Nasu et al. 1980; von Huene et al. 1982; Koike and Machida 2001), though the calculated uplift rate on land is smaller than the observed $(0.2-0.4 \mathrm{~mm} /$ year). This deformation pattern is produced by the tectonic erosion, which causes the 
landward migration of arc-trench topography maintained by the steady subduction (Hashimoto et al. 2008). Case 1 thus explains long-term uplift and coseismic subsidence but it cannot explain subsidence before the earthquake. This pattern holds for any $d \geq H$ cases where the rupture propagates down into the asthenosphere.

Figure $3 \mathrm{e}, \mathrm{f}$ shows temporal change in the effects of the viscoelastic response to past great earthquakes compared with the interseismic locking effect. Locking and viscoelastic effects are calculated by separately evaluating the second and third terms of the right-hand side of Eq. (1), respectively. Note that the vertical scale is different between Fig. 3e, f, but the locking effect (dashed line) is the same for both panels. The effect of the viscoelastic response is to compensate for the coseismic gravitational perturbations and to propagate deformation to greater distance (e.g., Fukahata and Matsu'ura 2006). The persistent uplift observed on land over time is due to the viscoelastic effect where the initial uplift offshore caused by rebound of coseismic subsidence migrates landward. In contrast, the locking effect causes strong compression. It creates uplift offshore, but little deformation on land.

Figure 4 shows the result for Case 2. Coseismic subsidence on land decays westward, as in Case 1 (Fig. 4a). Also similar to Case 1, we see a decrease and a landward shift of postseismic uplift for the first 100 years in the earthquake cycle (Fig. 4c). However, after 200 years, onshore uplift changes to subsidence and offshore subsidence changes to uplift (Fig. 4d). The onshore region then continues to subside (Fig. 4a, d). Just before the next earthquake, the rate of subsidence is around $5 \mathrm{~mm} /$ year. With the next earthquake, the onshore region subsides further, but net displacement for the cycle is uplift (Fig. 4b). As stated in "Earthquake cycle model with dislocations" section, long-term displacement is not dependent on the interseismic process, so Fig. $4 \mathrm{~b}$ is the same as Fig. 3b, showing the displacement accumulation rate of $\sim 0.08 \mathrm{~mm} /$ year on land. Case 2 consistently explains both long-term uplift and late-interseismic/coseismic subsidence.

Figure 4e, f shows the locking and viscoelastic effects. We see that both effects work differently from their counterparts in Fig. 3. If the rupture stops within lithosphere, stress in the vicinity of the lower edge of the rupture is not relaxed within an earthquake cycle. Deformation related to viscoelastic relaxation is dominantly expressed as downward flexure of the plate in the offshore region, with a related small uplift on land. For Case 2, the magnitude of the viscoelastic effect is around $30 \mathrm{~mm} /$ year in the first 100 years, but drops to $\sim 5 \mathrm{~mm} /$ year at 500 years. The locking effect on land is constant in time at $-10 \mathrm{~mm}$ /year (subsidence). Thus, we see that locking and viscoelastic responses are successively dominant effects; viscoelastic uplift dominates at the beginning of the earthquake cycle, and subsidence due to locking becomes more important later. The existence of a steady slip area below $\Sigma_{P}$ within the lithosphere is important; compared to Case 1 it amplifies both offshore uplift and land subsidence for the locking profile due to compression (dashed line).

Figure 5 shows how deformation patterns in the coseismic, late-interseismic (just before the earthquake), and long-term periods vary with changes in $H, d, \eta_{a}$, and $v_{e}$. We examined the effect for Case 2 of varying one parameter (e.g., $d$ ) while keeping the other three fixed (e.g., $H=35 \mathrm{~km}, \eta_{a}=10^{19} \mathrm{~Pa} \mathrm{~s}$, and $v_{e}=3 \mathrm{~mm} /$ year). The pattern of coseismic deformation strongly depends on $d$ (Fig. 5a). The observed subsidence pattern is met for $25 \mathrm{~km} \leq d<40 \mathrm{~km}$; subsidence on the land area increases seaward. Figure $5 \mathrm{~b}-\mathrm{d}$ shows the $d, H$, and $\eta_{a}$ dependence in late-interseismic (preseismic) pattern. The subsidence area can shift several tens of kilometers laterally with an increase in $d$ and $H$ (Fig. 5b, c). High values of $H$ lead to rapid uplift of the Pacific coast before the earthquake. Viscosity in the asthenosphere $\eta_{a}$ affects the amount of uplift rate, particularly for the central to western part of NE Japan (Fig. 5d). Long-term (permanent) deformation depends on $H$ and $v_{e}$ and its change is unremarkable (Fig. 5e, f). Long-term uplift onshore can be explained by $\mathrm{H} \geq 30 \mathrm{~km}$. As the first term of Eq. (1) shows, long-term uplift is proportional to $v_{e}$ and does not change its spatial pattern. The observed long-term uplift rate $(0.2-0.4 \mathrm{~mm} /$ year) may be explained by $v_{e} \geq 9 \mathrm{~mm} /$ year though it is three times greater than the geological estimates of $3 \mathrm{~mm} /$ year (von Huene and Lallemand 1990). To summarize, observed uplift/subsidence patterns are satisfied in the range of $30 \mathrm{~km} \leq H \leq 40 \mathrm{~km}, 25 \mathrm{~km} \leq d<H$, and $\eta_{a} \leq 2 \times 10^{19}$ Pa s.

\section{Discussion and conclusions}

We tackled the problem of a mismatch between longterm uplift versus late-interseismic/coseismic subsidence associated with the 2011 Tohoku earthquake in NE Japan, using a simple and consistent earthquake cycle model accounting for the effects of viscoelastic relaxation and tectonic erosion (Matsu'ura and Sato 1989; Sato and Matsu'ura 1993; Hashimoto et al. 2008). The model behaves differently in the case of a megathrust that ruptures completely through the lithosphere (Case 1) and a rupture that stops within the lithosphere (Case 2). Case 2 can account for the uplift/subsidence mismatch. In this case, the viscoelastic response to the megathrust earthquake compensates for late-interseismic/coseismic subsidence in the early interseismic stage. The locking effect successively governs the late-interseismic stage and causes the late-interseismic subsidence on land assisted by the steady slip below the rupture area. Tectonic 

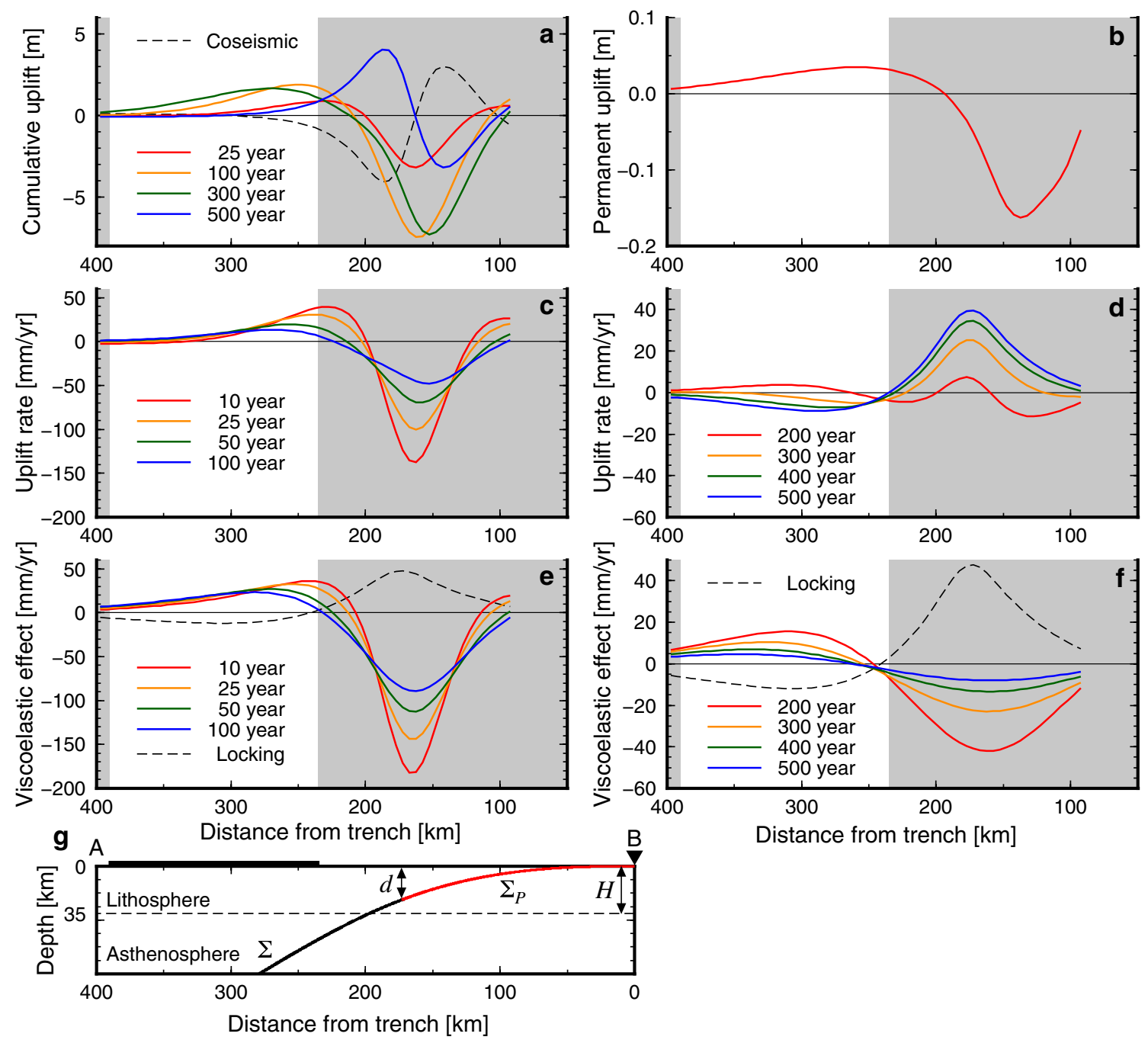

Fig. 4 Same as Fig. 3, but for Case 2

erosion partly explains the long-term uplift by landward movement of arc topography. Elastic half-space models (Ikeda 2014; Nishimura 2014) require locking at asthenospheric depths to fit the late-interseismic data, while our viscoelastic model does not.

This study neglects the effect of high viscosity of the Pacific slab. A strong-slab effect was investigated by Miyashita (1983), Pollitz et al. (2008), and Tanaka et al. (2009) for postseismic adjustment and by Shikakura (2008) for relaxed state. Focusing on the onland effect, these strong-slab models show that the addition of a slab does not change the spatial pattern of vertical deformation. Thus, the uplift/subsidence mismatch observed on the land remains the same for models with and without the slab, though it could change the rate of displacement by several tens of a percent (Pollitz et al. 2008).
Among discrepancies between the calculated and observed deformation patterns, the discrepancy in the late-interseismic pattern is the most interesting: The calculated pattern shows overall land subsidence (Fig. 4d), while uplift is observed in the western half of the land area (Fig. 1b). It is difficult to fit this lateinterseismic western uplift in the parameter space $(H$, $d, \eta_{a}$, and $v_{e}$ ), keeping consistency with the coseismic and long-term constraints (Fig. 5). One interpretation might be that the western uplift reflects rapid shortening along the western coast (Sato 1989; Okada and Ikeda 2012). Also, lithospheric thinning due to the high temperature beneath volcanoes would be important, which could cause stress concentration and localized deformation (Shibazaki et al. 2008, 2016; Muto et al. 2016). 

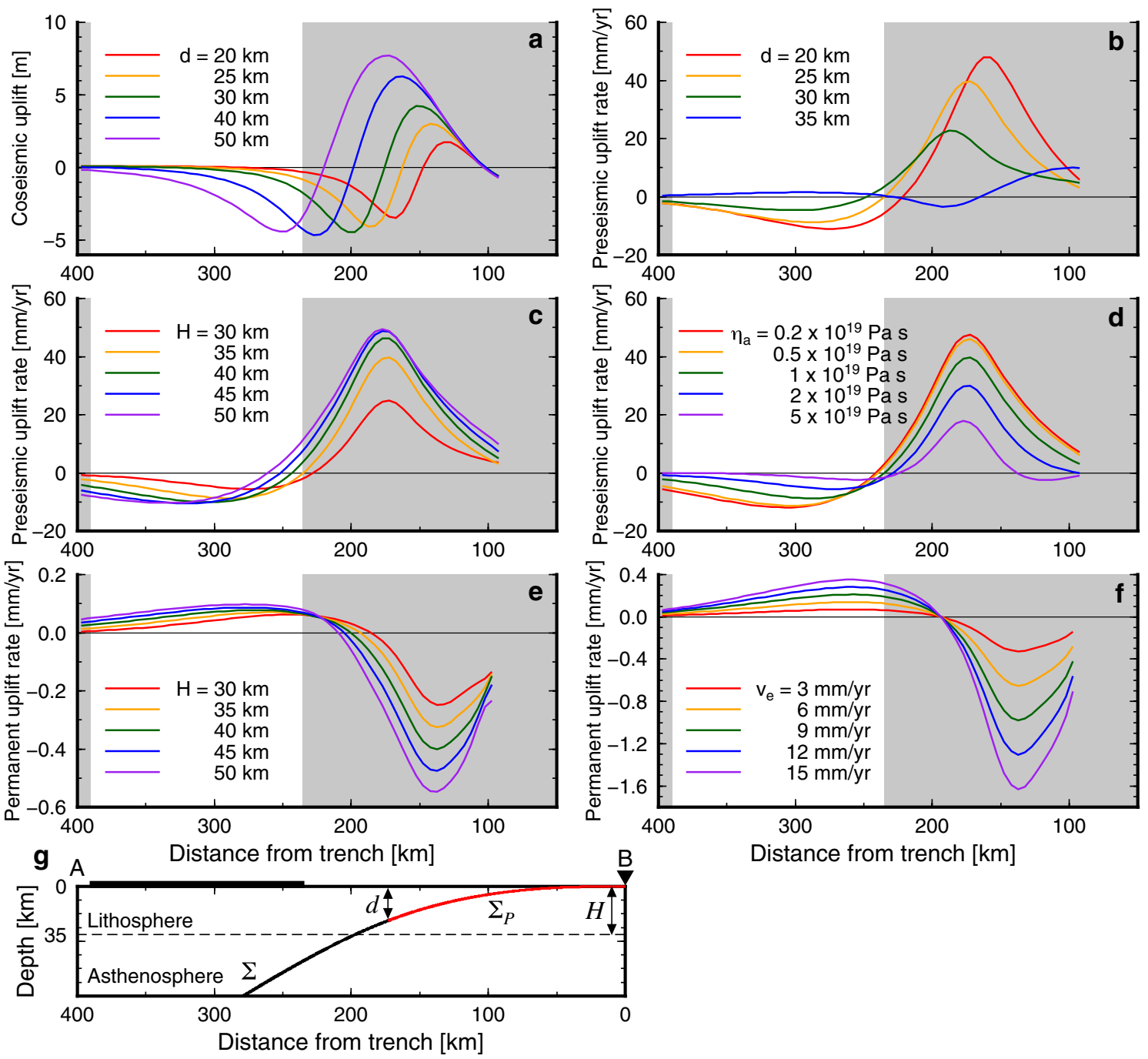

B Distance from trench $[\mathrm{km}]$

Fig. 5 Effects of lithospheric thickness $H$, depth to lower edge of periodic rupture area $d$, viscosity in the asthenosphere $\eta_{a}$, and tectonic erosion rate $v_{e}$ with respect to Case 2 on uplift profiles in different earthquake cycle stages. a Effect of $d$ on coseismic uplift. b Effect of $d$ on preseismic (just before the earthquake) uplift rate. $\mathbf{c}$ Effect of $H$ on preseismic uplift rate. $\mathbf{d}$ Effect of $\eta_{a}$ on preseismic uplift rate. e Effect of $H$ on permanent (longterm) uplift rate. $\mathbf{f}$ Effect of $v_{e}$ on permanent uplift rate. $\mathbf{g}$ Geometry of plate interface and rupture area for Case 2

The calculated permanent uplift rate $(\sim 0.08 \mathrm{~mm} /$ year for $v_{\mathrm{e}}=3 \mathrm{~mm} /$ year) is somewhat smaller than the observed (0.2-0.4 mm/year, Fig. 1a). Considering the uncertainty of $v_{e}$ or $T_{e}$ (duration of tectonic erosion), this effect can explain about half of the observed data. As Hashimoto et al. (2008) discussed, this shortfall may be due to indirect effects such as crustal thickening due to horizontal shortening and possible magmatic underplating, which expectedly causes uplift (e.g., Tajikara 2004; Ikeda 2014). Another possibility might be plastic deformation within the lithosphere during the interseismic stage that accumulates over multiple earthquake cycles (van Dinther et al. 2013).
As shown in Fig. 4, evolution of deformation in the offshore is much different from that in the onshore. Offshore observations obtained by both geodetic and geological methods could be important constraints on our earthquake cycle model.

For simplification, this model does not account for afterslip. Since postseismic adjustments that occur in the several years after the megathrust earthquake are governed by both viscoelastic relaxation and afterslip (e.g., Lubis et al. 2013; Yamagiwa et al. 2015; Freed et al. 2017), our analysis cannot accurately model early postseismic deformation. 


\section{Abbreviation}

NE Japan: Northeast Japan.

\section{Authors' contributions}

AH performed the computations and prepared the manuscript. TS contributed to the interpretation of the results. All authors contributed to the analysis and writing of the manuscript. All authors read and approved the final manuscript.

\section{Author details}

${ }^{1}$ Earthquake Research Institute, University of Tokyo, Yayoi 1-1-1, Bunkyo-ku, Tokyo 113-0032, Japan. ${ }^{2}$ Department of Earth Sciences, Graduate School of Science, Chiba University, Chiba 263-8522, Japan.

\section{Acknowledgements}

We would like to thank Editor Masato Furuya and two anonymous reviewers. We are grateful to Anne D. Van Horne for her constructive comments and grammatical correction. Yumi Amemiya digitized the Quaternary uplift data in NE Japan. Takuya Nishimura kindly provided us the leveling data. We thank the Geospatial Information Authority of Japan for providing GEONET data. This study was supported by the Special Project for Reducing Vulnerability for Urban Mega-earthquake Disasters and the Integrated Research Project on Seismic and Tsunami hazards around the Sea of Japan. Figures were prepared with the use of Generic Mapping Tool (Wessel and Smith 1998).

\section{Competing interests}

The authors declare that they have no competing interests.

Received: 7 September 2016 Accepted: 20 January 2017

Published online: 31 January 2017

\section{References}

Baba AK, Matsuda T, Itaya T, Wada Y, Hori N, Yokoyama M, Eto N, Kamei R, Zaman H, Kidane T, Otofuji Y (2007) New age constraints on counterclockwise rotation of NE Japan. Geophys J Int 171:1325-1341

Bird P (2003) An updated digital model of plate boundaries. Geochem Geophys Geosyst 4:1027. doi:10.1029/2001GC000252

Dambara T (1971) Synthetic vertical movements in Japan during the recent 70 years (in Japanese with English abstract). J Geod Soc Jpn 17:100-108

DeMets C, Gordon RG, Argus DF, Stein S (1994) Effect of recent revisions to the geomagnetic reversal time scale on estimates of current plate motions. Geophys Res Lett 21:2191-2194

Freed AM, Hashima A, Becker TW, Okaya DA, Sato H, Hatanaka Y (2017) Resolving depth-dependent subduction zone viscosity and afterslip from postseismic displacements following the 2011 Tohoku-oki, Japan Earthquake. Earth Planet Sci Lett 459:279-290. doi:10.1016/j.epsl.2016.11.040

Fukahata Y, Matsu'ura M (2005) General expressions for internal deformation fields due to a dislocation source in a multilayered elastic half-space. Geophys J Int 161:507-521

Fukahata Y, Matsu'ura M (2006) Quasi-static internal deformation due to a dislocation source in a multilayered elastic/viscoelastic half-space and an equivalence theorem. Geophys J Int 166:418-434

Hashimoto C, Fukui K, Matsu'ura M (2004) 3-D modelling of plate interfaces and numerical simulation of long-term crustal deformation in and around Japan. Pure Appl Geophys 161:2053-2068

Hashimoto C, Sato T, Matsu'ura M (2008) 3-D simulation of steady plate subduction with tectonic erosion: current crustal uplift and free-air gravity anomaly in northeast Japan. Pure Appl Geophys 165:567-583. doi:10.1007/s00024-008-0321-0

Ikeda Y (2003) Discrepancy between geologic and geodetic strain rates (in Japanese). Chikyu Monthly 25:125-129

Ikeda Y (2014) Strain buildup in the Northeast Japan orogen with implications for gigantic subduction earthquakes. Episodes 37:234-245

Kato T (1983) Secular and earthquake-related vertical crustal movements in Japan as deduced from tidal records (1951-1981). Tectonophysics 97:183-200

Koike K, Machida H (2001) Atlas of Quaternary marine terraces in the Japanese Islands (in Japanese). University of Tokyo Press, Tokyo
Kunimi T, Takano Y, Suzuki M, Saitou T, Narita T, Okamura S (2001) Vertical crustal movements in Japan estimated from the leveling observations data for the past 100 years (in Japanese). J Geograph Surv Inst 96:23-37

Lubis AM, Hashima A, Sato T (2013) Analysis of afterslip distribution following the 2007 September 12 southern Sumatra earthquake using poroelastic and viscoelastic media. Geophys J Int 192:18-37

Matsu'ura M, Sato T (1989) A dislocation model for the earthquake cycle at convergent plate boundaries. Geophys J Int 96:23-32

Matsu'ura T, Furusawa A, Saomoto H (2008) Late Quaternary uplift rate of the northeastern Japan arc inferred from fluvial terraces. Geomorphology 95:384-397

Matsu'ura T, Furusawa A, Saomoto H (2009) Long-term and short-term vertical velocity profiles across the forearc in the NE Japan subduction zone. Quat Res 71:227-238

Mavrommatis AP, Segall P, Johnson KJ (2014) A decadal-scale deformation transient prior to the 2011 Mw 9.0 Tohoku-oki earthquake. Geophys Res Lett 41:4486-4494

Mavrommatis AP, Segall P, Uchida N, Johnson KJ (2015) Long-term acceleration of aseismic slip preceding the Mw 9 Tohoku-oki earthquake: constraints from repeating earthquakes. Geophys Res Lett 42:9717-9725

Miyashita K (1983) Surface displacement patterns associated with asthenospheric stress relaxation following major underthrust earthquakes (in Japanese with English abstract). Zisin (J Seismol Soc Japan) 36:541-550

Muto J, Shibazaki B, linuma T, Ito Y, Ohta Y, Miura S, Nakai Y (2016) Heterogeneous rheology controlled postseismic deformation of the 2011 Tohoku-Oki earthquake. Geophys Res Lett 43:4971-4978. doi:10.1002/2016GL068113

Nasu N, von Huene R, Ishiwada Y, Langseth M, Bruns T, Honza E (1980) Interpretation of multichannel seismic reflection data, Legs 56 and 57, Japan Trench transect, deep sea drilling project. Initial Rep Deep Sea Drill Proj 56/57:489-503

Nishimura T (2014) Pre-, co-, and post-seismic deformation of the 2011 Tohoku-oki earthquake and its implication to a paradox in short-term and long-term deformation. J Disaster Res 9:294-302

Nishimura T, Hirasawa T, Miyazaki S, Sagiya T, Tada T, Miura S, Tanaka K (2004) Temporal change of interplate coupling in northeastern Japan during 1995-2002 estimated from continuous GPS observations. Geophys J Int 157:901-916

Nishimura T, Munekane H, Yarai H (2011) The 2011 off the Pacific coast of Tohoku Earthquake and its aftershocks observed by GEONET. Earth Planets Space 63:631-636. doi:10.5047/eps.2011.06.025

Okada S, Ikeda Y (2012) Quantifying crustal extension and shortening in the back-arc region of Northeast Japan. J Geophys Res 117:B01404. doi:10.10 29/2011 JB008355

Otofuji Y, Matsuda T, Nohda S (1985) Opening mode of the Japan Sea inferred from the palaeomagnetism of the Japan Arc. Nature 317:603-604

Pollitz F, Banerjee P, Grijalva K, Nagarajan B, Bürgmann R (2008) Effect of 3-D viscoelastic structure on post-seismic relaxation from the $2004 \mathrm{M}=9.2$ Sumatra earthquake. Geophys J Int 173:189-204

Sagiya T (2015) Paradoxical vertical crustal movement along the Pacific coast of northeast Japan. Int Assoc Geod Symp 145:73-78. doi:10.1007/1345_2015_189

Sato H (1989) Degree of deformation of late Cenozoic strata in the Northeast Honshu arc (in Japanese with English abstract). Mem Geol Soc Japan $32: 257-268$

Sato H (1994) The relationship between late Cenozoic tectonic events and stress field and basin development in northeast Japan. J Geophys Res 99:22261-22274

Sato T, Matsu'ura M (1988) A kinematic model for deformation of the lithosphere at subduction zones. J Geophys Res 93:6410-6418

Sato T, Matsu'ura M (1993) A kinematic model for evolution of island arctrench systems. Geophys J Int 114:512-530

Savage JC, Prescott WH (1978) Asthenospheric readjustment and the earthquake cycle. J Geophys Res 83:3369-3376

Sawai Y, Namegaya Y, Okamura Y, Satake K, Shishikura M (2012) Challenges of anticipating the 2011 Tohoku earthquake and tsunami using coastal geology. Geophys Res Lett 39:L21309. doi:10.1029/2012GL053692

Sawai Y, Namegaya Y, Tamura T, Nakashima R, Tanigawa K (2015) Shorter intervals between great earthquakes near Sendai: scour ponds and a sand layer attributable to A.D. 1454 overwash. Geophys Res Lett 42:4795-4800. doi:10.1002/2015GL064167 
Sharp WD, Clague DA (2006) 50-Ma initiation of Hawaiian-Emperor bend records major change in Pacific plate motion. Science 313:1281-1284

Shibazaki B, Garatani K, Iwasaki T, Tanaka A, Ito Y (2008) Faulting processes controlled by the nonuniform thermal structure of the crust and uppermost mantle beneath the northeastern Japanese island arc. J Geophys Res 113:B08415. doi:10.1029/2007JB005361

Shibazaki B, Okada T, Muto J, Matsumoto T, Yoshida T, Yoshida K (2016) Heterogeneous stress state of island arc crust in northeastern Japan affected by hot mantle fingers. J Geophys Res 121:3099-3117. doi:10.1002/201 5JB012664

Shikakura Y (2008) Numerical simulation with a finite element method for the development of mechanical and thermal structure in subduction zones. PhD Thesis, Univ Tokyo

Suito H, Nishimura T, Tobita M, Imakiire T, Ozawa S (2011) Interplate fault slip along the Japan Trench before the occurrence of the 2011 off the Pacific coast of Tohoku Earthquake as inferred from GPS data. Earth Planets Space 63:615-619. doi:10.5047/eps.2011.06.053

Suwa Y, Miura S, Hasegawa A, Sato T, Tachibana K (2006) Interplate coupling beneath NE Japan inferred from three-dimensional displacement field. J Geophys Res 111:B04402. doi:10.1029/2004JB003203

Tajikara M (2004) Vertical crustal movements of the northeast Japan arc in late Quaternary time. PhD Thesis, Univ Tokyo

Tajikara M, Ikeda Y (2005) Vertical crustal movement and development of basin and range topography in the middle part of the Northeast Japan arc estimated from fluvial/marine terrace data (in Japanese with English abstract). Quat Res (Daiyonki Kenkyu) 44:229-245

Tanaka Y, Klemann V, Fleming K, Martinec Z (2009) Spectral finite element approach to postseismic deformation in a viscoelastic self-gravitating spherical Earth. Geophys J Int 176:715-739 van Dinther Y, Gerya TV, Dalguer LA, Mai PM, Morra G, Giardini D (2013) The seismic cycle at subduction thrusts: insights from seismo-thermomechanical models. J Geophys Res 118:6183-6202. doi:10.1002/201 3JB010380

von Huene R, Lallemand S (1990) Tectonic erosion along the Japan and Peru convergent margins. Geol Soc Am Bull 102:704-720

von Huene R, Langseth M, Nasu N, Okuda H (1982) A summary of Cenozoic tectonic history along the IPOD Japan Trench transect. Geol Soc Am Bull 93:829-846

Wessel P, Smith WHF (1998) New, improved version of the generic mapping tools released. EOS Trans AGU 79:579

Yagi Y, Fukahata Y (2011) Rupture process of the 2011 Tohoku-oki earthquake and absolute elastic strain release. Geophys Res Lett 38:L19307. doi:10.10 29/2011GL048701

Yamagiwa S, Miyazaki S, Hirahara K, Fukahata Y (2015) Afterslip and viscoelastic relaxation following the 2011 Tohoku-oki earthquake (Mw9.0) inferred from inland GPS and seafloor GPS/Acoustic data. Geophys Res Lett 42:66-73

Yamanaka Y, Kikuchi M (2004) Asperity map along the subduction zone in northeastern Japan inferred from regional seismic data. J Geophys Res 109:B07307. doi:10.1029/2003JB002683

Yoshiyama A, Yanagida M (1995) Uplift rates estimated from relative heights of fluvial terrace surfaces and valley bottoms (in Japanese with English abstract). J Geogr 104:809-826

\section{Submit your manuscript to a SpringerOpen ${ }^{\circ}$ journal and benefit from:}

- Convenient online submission

- Rigorous peer review

- Immediate publication on acceptance

- Open access: articles freely available online

- High visibility within the field

- Retaining the copyright to your article

Submit your next manuscript at springeropen.com 